\title{
PROBLEM SOLVING IN THE CONTEXT OF COMPUTATIONAL THINKING
}

\author{
${ }^{* 1}$ Swasti Maharani, ${ }^{2}$ Muhammad Noor Kholid, ${ }^{3}$ Lingga Nico Pradana, ${ }^{4}$ Toto Nusantara \\ ${ }^{1,4}$ Universitas Negeri Malang \\ ${ }^{2}$ Universitas Muhammadiyah Surakarta \\ ${ }^{1,3}$ Universitas PGRI Madiun
}

\section{Article Info}

\section{Article history:}

Received Dec 16, 2018

Revised May 15, 2019

Accepted Sept 2, 2019

\section{Keywords:}

Computational Thinking,

Graph,

Problem Solving,

Polya,

Mathematics Education

\begin{abstract}
Computational thinking is needed in the 21 st century, where we live in an era of digitalization. Also, there is a global movement to incorporate computational thinking into the education curriculum, especially Mathematics education. The different of this research with others is this research compares the Polya problem solving and computational thinking. This research was conducted to find out how the relationship/relationship of the Polya problem-solving with the steps of computational thinking. The method used in this research is descriptive qualitative. The subject of this study was mathematics education students. The results showed that the relationship between problem-solving and computational thinking of respondent when solving the problem is when defining the problem in the context of problem-solving, the respondent performs the stage of decomposition and abstraction in the context of computational thinking. During the planning process of the solution process, respondents carried out the generalization stage. When the scene is carrying out the plan and the problem solver to look back to evaluate the solution, the respondent performs the debugging and algorithmic steps.
\end{abstract}

Copyright (0) 2019 IKIP Siliwangi. All rights reserved.

\section{Corresponding Author:}

Swasti Maharani,

Department of Mathematics Education,

Universitas PGRI Madiun,

Jl. Setiabudi No.85, Kanigoro, Kota Madiun, Jawa Timur 63118, Indonesia

Email: swasti.mathedu@unipma.ac.id

\section{How to Cite:}

Maharani, S., Kholid, M. N., Pradana, L. N., \& Nusantara, T. (2019). Problem solving in the context of computational thinking. Infinity, 8(2), 109-116.

\section{INTRODUCTION}

In the current era of globalization in the 21st century, digital technology plays an important role in everyday life. In response to the increasing demand to compete in the global economy, countries need to prepare students with appropriate technical knowledge and communication skills to compete (Tsai \& Tsai, 2017). Combining knowledge and technology is a solution to a problem that will become a trend (Voskoglou \& Buckley, 2012). One step in dealing with this is to include computational thinking into the curriculum (Bower, Wood, Howe, \& Lister, 2017; Weintrop et al., 2016; Voogt, Fisser, Good, Mishra, \& Yadav, 2015; Geary, Saults, Liu, \& Hoard, 2000). However, this has not been done in Indonesia. 
Computational thinking is a basic ability for students in education, which is the same basis as the ability to read, write and arithmetic calculations (Zhong, Wang, Chen, \& $\mathrm{Li}, 2016 ; \mathrm{Hu}, 2011)$. Learning by using computational thinking, as a basic skill throughout the school curriculum, will enable students to learn abstract thinking, algorithmic and logical, as well as ready to solve complex and open problems. Supported by Adler \& Kim (2017) who said that honing computational thinking would be beneficial in education, and beneficial for their future. Computational thinking is everyone's basic ability to learn which is an important preparation for the future to educate young people with computational thinking. Activity-based learning strategies are strategies to help young people's cognitive growth, and can guide their learning effectively through manipulation and real expressions. (Cho \& Lee, 2017). Computational thinking is considered an important competency because students currently not only work in fields affected by computing, but also need to face computing in their daily lives and in today's global economy (Bower et al., 2017; Grover \& Pea, 2013).

One of the subjects in the school curriculum is mathematics, so it does not rule out the possibility that applying computational thinking in mathematics can improve students' conceptual mathematics. Mathematics requires learning activities that provide direct experience to encourage problem solving skills (Sung, Ahn, \& Black, 2017). Computational thinking and learning mathematics have reciprocal relationships, using computing to enrich mathematics and science learning, and apply the context of mathematics and science to enrich computational learning (Weintrop et al., 2016).

The main motivation for introducing the practice of CT (Computational Thinking) into the mathematics classroom is in response to increasingly computerized disciplines because they are practiced in the professional world (Acharya, 2016). Mathematical ability is considered a core factor that predicts students' ability to learn (Grover \& Pea, 2013). Some researchers put forward convincing arguments that mathematical thinking plays an important role in CT (Gadanidis, 2017; Rambally, 2017; Son \& Lee, 2016) because solving math problems is a construction process (Benakli, Kostadinov, Satyanarayana, \& Singh, 2017; Lockwood, DeJarnette, Asay, \& Thomas, 2016; Merle, 2016). The construction process to complete this solution requires an analytical perspective to solve unique and fundamental problems for students. Based on the results of previous studies, computational thinking can improve the mastery of material number sense and arithmetic abilities (Hartnett, 2015) which is influenced by thinking style, academic success and attitude towards mathematics (Durak \& Saritepeci, 2017). In addition, computational thinking can also be influenced by the level of class and the duration of ownership of mobile technology (Korucu, Gencturk, \& Gundogdu, 2017). Cognitive habits that can assist in the development of computational thinking are spatial reasoning and intelligence (Ambrosio, Almeida, Macedo, \& Franco, 2014; Yasar, Maliekal, Veronesi, \& Little, 2017).

Problems have an important role in mathematics. Most of the learning in school is designed in such a way based on mathematical problems (Reiss \& Törner, 2007). During this time in solving students' math problems more on solving the problem. Solving the problems that are often reviewed are steps from Polya including the problem identification stage, planning problems, implementing the plan, and checking the answers (Reiss \& Törner, 2007). In addition, computational thinking also has a role in solving mathematics, so it needs to be revealed how to solve mathematical problems in the context of computational thinking. 


\section{METHOD}

This research is a qualitative descriptive research with the respondent is 30 of mathematics education students at Universitas Negeri Malang. The characteristics of the subject is mathematics education students who have been finished graph subject. The instrument used is one math problem consisting of problem solving question. The technique used in the determination of the respondent is the method of random sampling, because this research want to know the relationship of Polya problem solving and computational thinking. All of students do the Polya problem solving on solve the mathematics problem. There are five stages in this study. First, giving problem solving question to respondent and asking the respondent to do it. The question is "map can be easily represented by graph. A country symbolized by a vertex and edge (line between two vertexes) describes two neighboring countries on graph. The picture below represents a map into the graph. Specify an appropriate map for the given graph!" (Figure 1)
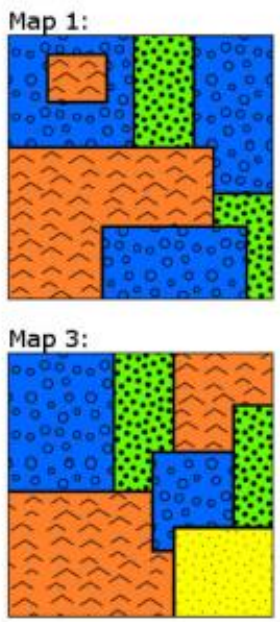

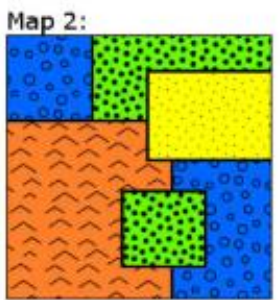

Map 4:

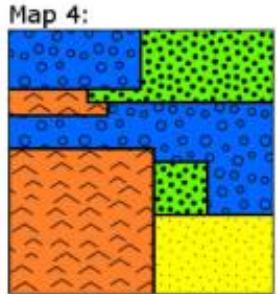

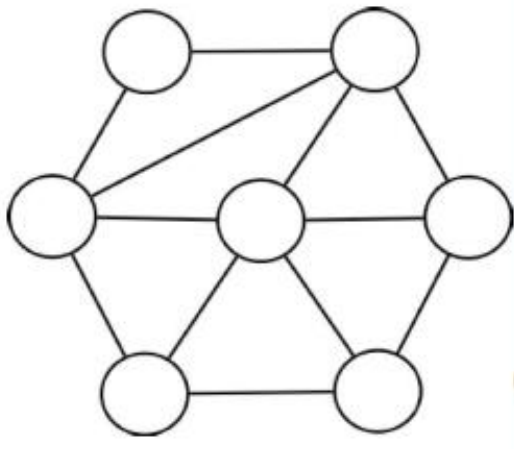

Figure 1. Question

The second stage, observing. Researchers recorded directly respondent and also by recording directly any activity of research respondents when solving problem solving question based on the observation sheet to classify the tendency of computational thinking. Observations focused on behavioral trends in performing computational thinking during problem solving task. The third stage, analyzing the components of computational thinking that appear on respondent of research based on the results of direct observation. The results of the analysis in the form of conclusions about the behavior of research respondents whether the responden to do computational thinking or not. Fourth, perform triangulation of data to confirm the results of the analysis is the conclusion whether the responden to do computational thinking or not by conducting an in-depth interview (in-deep interview). Interview guidelines used are with a structured and open format. In addition to interviews, there is also a data reduction stage that is not required after in-depth interviews. Finally, summarizes the results of the analysis of the components of computational thinking of prospective mathematics teachers based on the results of observation and interviews so that data can be obtained by a computational thinking of the students of mathematics education in solving the problem. The results obtained at the last stage is the classification of computational thinking of prospective mathematics teachers when solving the problem. The indicator of computational thinking when solving the problem can be viewed on the Table 1. 
Table 1. Indicator of computational thinking when solving the problem

\begin{tabular}{cl}
$\begin{array}{c}\text { The component of } \\
\text { computational thinking }\end{array}$ & \multicolumn{1}{c}{ Students activity } \\
\hline Abstraction & $\begin{array}{l}\text { students can decide on an object to use or reject, can be } \\
\text { interpreted to separate important information from } \\
\text { information that is not used }\end{array}$ \\
\hline Generalization & $\begin{array}{l}\text { the ability to formulated a solution into general form so that } \\
\text { can be applied to different problems, can be interpreted as } \\
\text { the use of variables in resolving solutions }\end{array}$ \\
\hline Decomposition & $\begin{array}{l}\text { the ability to break complex problems into simpler ones } \\
\text { that are easier to understand and solve }\end{array}$ \\
\hline Algorithmic & $\begin{array}{l}\text { the ability to design step by step an operation/action how } \\
\text { the problems are solved }\end{array}$ \\
\hline Debugging & the ability to identify, dispose of, and correct errors \\
\hline
\end{tabular}

\section{RESULTS AND DISCUSSION}

\subsection{Results}

The results show that the students can solve the problem with computational thinking components. The responden need about five minutes to read the problem. Responden known that map 1 and map 2 didn't correct answer. This step responden did decomposition step, because responden break the map from 4 into 2 maps. If in this stage of problem solving, enter the stage define the problem. The respondent draws vertices and edges according to the problem, gives a symbol on each vertex, separating any letters connected to two countries, three countries and so on. This process/stage can be called the abstraction stage because the respondent can separate important information that can be used. The way to do that is by identifying each map (map 3 and 4) which is in accordance with the graph drawing that he made earlier. This stage can be said to be the generalization stage, because the respondent can make a general form which in this context is a graph on a question that has been given a symbol. This process can be called planning the use of strategies in problem solving.

When working on, the respondent realizes that there is an error he made that there is a writing error that is "connected" is replaced with "neighbor". This stage can be called the debugging stage, because the respondent corrects the error. In working on map 3, the respondent draws a map and gives a symbol to each country, the same as repeat as in the initial example. After finding the answer, namely map 3. then the respondent checks the map 4. the respondent draws map 4 and gives the symbol the same as the previous way. Fear of map 4 is also true because questions are not multiple choice questions. At this stage, it can be said that respondents carried out an algorithmic stage. When viewed from the side of problem solving this stage enters the implementation phase of the plan / problem solving strategy while checking the answers. The answer of responden can be viewed on the Figure 2. 


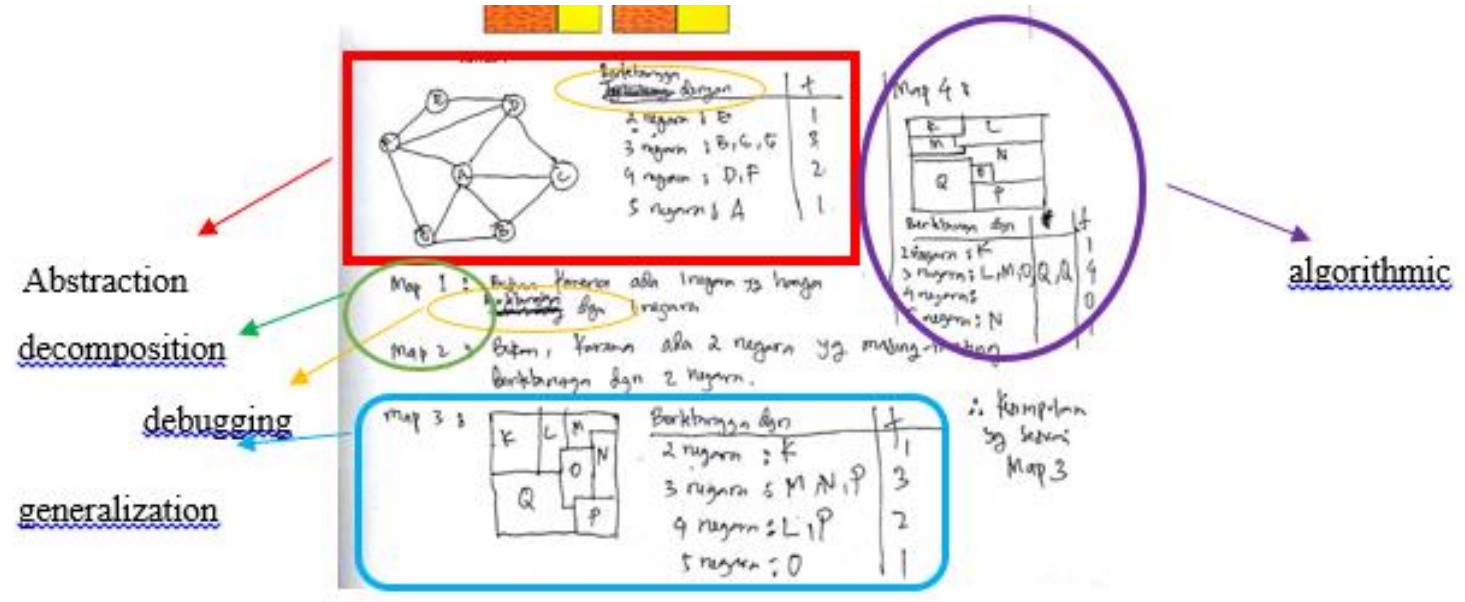

Figure 2. answer one of respondent

Figure 2 show that computational thinking student on solving mathematics problem especially graph. First, the student did the abstraction, then decomposition, debugging, generalization, and the last algorithmic.

\subsection{Discussion}

Previous studies discussed about what it might mean and what we might do about computational thinking ( $\mathrm{Hu}, 2011)$, problem solving in the mathematics classroom in Germany (Voskoglou \& Buckley, 2012; Voskoglou, 2013) implications for teacher knowledge in K-6 computational thinking curriculum framework (Angeli et al., 2016), the possibility of improving computational thinking through activity based learning (Cho \& Lee, 2017), a framework of curriculum design for computational thinking development in K-12 education (Kong, 2016). The level of participants' computational thinking skills differed significantly in terms of their grade level, not significantly different in terms of their gender (Korucu et al., 2017).

The steps taken by respondents are first decomposition, abstraction, generalization, debugging and algorithmic. These steps do not match the order of computational thinking indicators. This is in line with the results of research conducted by Voskoglou \& Buckley (2012) which states that the sequence of problem solving steps seen from computational thinking does not have to be in order. When performing the decomposition and abstraction stage, the respondent understands the problem by reading the questions carefully for five minutes, and determining that maps 1 and 2 do not fulfill the reasons. This means that respondents have understood what was asked about the problem and identified the reasonable parts (Reiss \& Törner, 2007). Next step, the generalization stage of the respondent can make a general form which in this context is a graph on the question that has been given a symbol. At this stage if viewed in terms of problem solving can enter the planning process of the solution stage because the respondent tries to make his own formula to complete, it is a strategy to solve. The respondent identifying auxiliary problems, changing the formulation, or checking the relevance of the data (Reiss \& Törner, 2007).

Respondents did debugging while the work takes place, before doing algorithmic respondents have debugged. Then the respondent performs an algorithmic process that is completing map 3 and map 4 according to the general form that was made earlier. In this process the respondent also checked the map 4 even though he had found an answer 
namely map 3. In this case the respondent did the stage carrying out the plan and the problem solver to look back and to evaluate the solution. This means to check every single part of the solution and to make sure (or, preferably, to prove) that it is correct and to show that it is correct and all arguments are valid (Reiss \& Törner, 2007).

In general, computational thinking is a problem solving who not only on information technology but on mathematics education too. Students who use the computational thinking on solving the mathematics problem would be easy to solve other mathematics problems.

\section{CONCLUSION}

The relationship between problem-solving and computational thinking of respondent when solving the problem is when defining the problem in the context of problem-solving, the respondent performs the stage of decomposition and abstraction in the context of computational thinking. During the planning process of the solution process, respondents carried out the generalization stage. When the scene is carrying out the plan and the problem solver to look back to evaluate the solution, the respondent performs the debugging and algorithmic steps.

Computational thinking supported students to solve the mathematics problem. The development of computational thinking was needed for future research that will be affected to learning especially mathematics learning. For example, the assessment of computational thinking, the characteristic of computational thinking, the expansive of each component of computational thinking and others.

\section{ACKNOWLEDGEMENTS}

We want to thank the anonymous referees for their constructive criticism and many helpful comments and suggestions, which undoubtedly improved the quality of the paper. Thank you to the Ministry of Research, Technology, and the Higher Education Republic of Indonesia.

\section{REFERENCES}

Adler, R. F., \& Kim, H. (2017). Enhancing future K-8 teachers' computational thinking skills through modeling and simulations. Journal Education and Information Technologies, 23(4), 1501-1514.

Ambrosio, A. P., Almeida, L. S., Macedo, J., \& Franco, A. H. R. (2014). Exploring core cognitive skills of computational thinking. In Psychology of Programming Interest Group Annual Conference 2014 (PPIG 2014), 25-34.

Angeli, C., Voogt, J., Fluck, A., Webb, M., Cox, M., Malyn-Smith, J., \& Zagami, J. (2016). A K-6 computational thinking curriculum framework: Implications for teacher knowledge. Journal of Educational Technology \& Society, 19(3).

Acharya, K. P. (2016). Fostering critical thinking practices at primary science classrooms in Nepal. Research in Pedagogy, 6(2), 1-7.

Benakli, N., Kostadinov, B., Satyanarayana, A., \& Singh, S. (2017). Introducing computational thinking through hands-on projects using $\mathrm{R}$ with applications to calculus, probability and data analysis. International Journal of Mathematical Education in Science and Technology, 48(3), 393-427. 
Bower, M., Wood, L. N., Howe, C., \& Lister, R. (2017). Improving the Computational Thinking Pedagogical Capabilities of School Teachers. Australian Journal of Teacher Education, 42(3), 53-72.

Cho, Y., \& Lee, Y. (2017). Possibility of Improving Computational Thinking Through Activity Based Learning. Journal of Theoretical and Applied Information Technology, 95(18), 4385-4393.

Durak, H. Y., \& Saritepeci, M. (2017). Analysis of the relation between computational thinking skills and various variables with the structural equation model. Computers \& Education, 116, 191-202.

Gadanidis, G. (2017). Artificial intelligence, computational thinking, and mathematics education. The International Journal of Information and Learning Technology, 34(2), 133-139.

Geary, D. C., Saults, S. J., Liu, F., \& Hoard, M. K. (2000). Sex Differences in Spatial Cognition , Computational Fluency, and Arithmetical Reasoning. Journal of Experimental Child Psychology, 77, 337-353.

Grover, S., \& Pea, R. (2013). Computational Thinking in K - 12 : A Review of the State of the Field, 42(1), 38-43.

Hartnett, J. (2015). Teaching Computation in Primary School without Traditional Written Algorithms. In Proceedings of the 38th annual conference of the Mathematics Education Research Group of Australasia, 285-292.

$\mathrm{Hu}$, C. (2011). Computational Thinking - What It Might Mean and What We Might Do about It. In ITiCSE '11: Proceedings of the 16th annual joint conference on Innovation and technology in computer science education, 223-227.

Kong, S. (2016). A framework of curriculum design for computational thinking development in K-12 education. Journal of Computers in Education, 3(4), 377394.

Korucu, A., Gencturk, A., \& Gundogdu, M. (2017). Examination of the computational thinking skills of students. Journal of Learning and Teaching in Digital Age, 2(1), 11-19.

Lockwood, E., DeJarnette, A. F., Asay, A., \& Thomas, M. (2016). Algorithmic Thinking: An Initial Characterization of Computational Thinking in Mathematics. North American Chapter of the International Group for the Psychology of Mathematics Education.

Merle, L. J. (2016). Reflective learning and prospective teachers'conceptual understanding, critical thinking, problem solving, and mathematical communication skills. Research in Pedagogy, 6(2), 43-58.

Rambally, G. (2017). Integrating Computational Thinking in Discrete Structures. In Emerging Research, Practice, and Policy on Computational Thinking, 99-119.

Reiss, K., \& Törner, G. (2007). Problem solving in the mathematics classroom: The German perspective. ZDM - International Journal on Mathematics Education, 39(5-6), 431-441.

Son, J. W., \& Lee, J. E. (2016). Pre-Service Teachers' Understanding of Fraction Multiplication, Representational Knowledge, and Computational Skills. Mathematics Teacher Education and Development, 18(2), 5-28. 
Sung, W., Ahn, J., \& Black, J. B. (2017). Introducing Computational Thinking to Young Learners: Practicing Computational Perspectives Through Embodiment in Mathematics Education. Technology, Knowledge and Learning, 22(3), 443-463.

Tsai, M., \& Tsai, C. (2017). Applying online externally-facilitated regulated learning and computational thinking to improve students learning. Universal Access in the Information Society, 17(4), 811-820.

Voogt, J., Fisser, P., Good, J., Mishra, P., \& Yadav, A. (2015). Computational thinking in compulsory education: Towards an agenda for research and practice. Education and Information Technologies, 20(4), 715-728.

Voskoglou, M. G., \& Buckley, S. (2012). Problem solving and computational thinking in a learning environment. arXiv preprint arXiv:1212.0750.

Voskoglou, M. G. (2013). Problem solving, fuzzy logic and computational thinking. Egyptian Computer Science Journal, 37(1), 131-145.

Weintrop, D., Beheshti, E., Horn, M., Orton, K., Jona, K., Trouille, L., \& Wilensky, U. (2016). Defining Computational Thinking for Mathematics and Science Classrooms. Journal of Science Education and Technology, 25(1), 127-147.

Yasar, O., Maleikal, J., Veronesi, P., \& Little, L. J. (2017). The essence of computational thinking and tools to promote it. In American Society for Engineering Education.

Zhong, B., Wang, Q., Chen, J., \& Li, Y. (2016). An Exploration of Three-Dimensional Integrated Assessment for Computational Thinking. Journal of Educational Computing Research, 53(4), 562-590. 